\title{
Effect of weather parameters on yellow rust incidence of wheat under different growing environment
}

\author{
SARABJOT KAUR SANDHU* AND L. K. DHALIWAL
}

School of Climate Change and Agricultural Meteorology, Punjab Agricultural University, LUDHIANA (PUNJAB) INDIA

\section{ARITCLE INFO}

Received : 15.07 .2017

Revised : 08.09 .2017

Accepted : 20.09.2017

\section{KEY WORDS :}

Wheat, Yellow rust, Row spacing, Temperature, Relative humidity

*Corresponding author: Email : skchahal@pau.edu

\begin{abstract}
:
Yellow rust is the major wheat disease and is influenced by prevailing weather conditions. Field experiment was conducted to investigate the effect of weather parameters on yellow rust incidence under different growing environments. Wheat varieties HD 2967, PBW 550 and PBW 343 were sown under three row spacing viz., $15 \mathrm{~cm}, 22.5 \mathrm{~cm}$ and 30 $\mathrm{cm}$. Yellow rust incidence was recorded at weekly intervals. Disease incidence was higher (100\%) during Rabi 2012-13 as compared to 2013-14 (90\%). Among different row spacing the disease incidence was maximum $(100 \%)$ in $15 \mathrm{~cm}$ row spacing followed by $22.5 \mathrm{~cm}$ and minimum in $30 \mathrm{~cm}$ spacing during both the years. Among three varieties HD 2967 was highly resistant to yellow rust. During both the years maximum temperature, minimum temperature and sunshine hours were positively correlated whereas morning and evening relative humidity were negatively correlated with yellow rust incidence. Highly significant value of $\mathrm{R}^{2}$ (0.91 and 0.92 ) was found when maximum meteorological parameters were combined in PBW 550 and PBW 343, respectively.
\end{abstract}

How to view point the article : Sandhu, Sarabjot Kaur and Dhaliwal, L.K. (2017). Effect of weather parameters on yellow rust incidence of wheat under different growing environment. Internat. J. Plant Protec., 10(2) : 415-419, DOI : 10.15740/HAS/IJPP/10.2/415-419. 